\title{
Development of an Extension 'Primer' on Tree Registration Policy in Leyte: an Example of a Collaborative Material Design
}

\author{
Melissa Gordon ${ }^{1}$, Rotacio Gravoso ${ }^{2}$, Eduardo Mangaoang ${ }^{2}$ and \\ Edwin Balbarino ${ }^{2}$ \\ ${ }^{1}$ School of Natural and Rural Systems Management, The University of \\ Queensland Gatton, Queensland 4343, Australia \\ ${ }^{2}$ Visayas State University, Visca, Baybay, 6521-A Leyte, the Philippines
}

\begin{abstract}
Tree registration in the Philippines helps meet the legal requirements for harvesting and transport of timber, and is encouraged by the Philippines Government. To help improve information flow an extension primer was developed. The primer contains basic information on tree registration, harvesting, log transport and marketing. The development process involved input from staff of the Philippine Department of Environment and Natural Resources, tree farmers, furniture dealers, the Philippine National Police, the World Agroforestry Centre, Visayas State University and The University of Queensland. Key stakeholders were brought together at three workshops to review policy information and explore the interactions between, and differing opinions of, the various stakeholders. The primer has been distributed widely. Positive feedback has been obtained, although testing has shown that further improvements are possible. A revised version of the primer is to be produced.
\end{abstract}

Keywords: forestry extension, smallholder forestry, tree registration, harvest rights

\section{INTRODUCTION}

In the Philippines, commercial logging of natural forests is banned in all but two provinces, and tree farming is encouraged by the national government in order to reduce dependency on timber imports (Calub 2005). The Department of Environment and Natural Resources (DENR) through its Forest Management Service is responsible for forest administration. For anyone growing trees on privately-owned land, a certificate of Tree Plantation Ownership can be obtained on request from a Community Environment and Natural Resources (CENR) officer ${ }^{1}$. Figure 1 shows the

\footnotetext{
${ }^{1}$ Leyte Island falls within Region VIII of the Philippines and comprises the provinces of Leyte and Southern Leyte. As well as the DENR head office in Quezon City, each province in the Philippines has a provincial DENR office and a number of Community Environment and Natural Resource Offices (CENROs).

DOI: 10.32945/atr2933.2007
} 
CENRO areas of jurisdiction in Leyte. The tree registration process also requires certification of tree ownership from the local government unit (LGU) or mayor (DENR, 1997). Registration is only necessary if people wish to transport their timber to sell; it is not necessary for people using timber on-farm. Private landholders on Alienable and Disposable (A \& D) land, who wish to sell their timber, should thus register their trees in order to obtain a transport permit so they can harvest and sell timber.

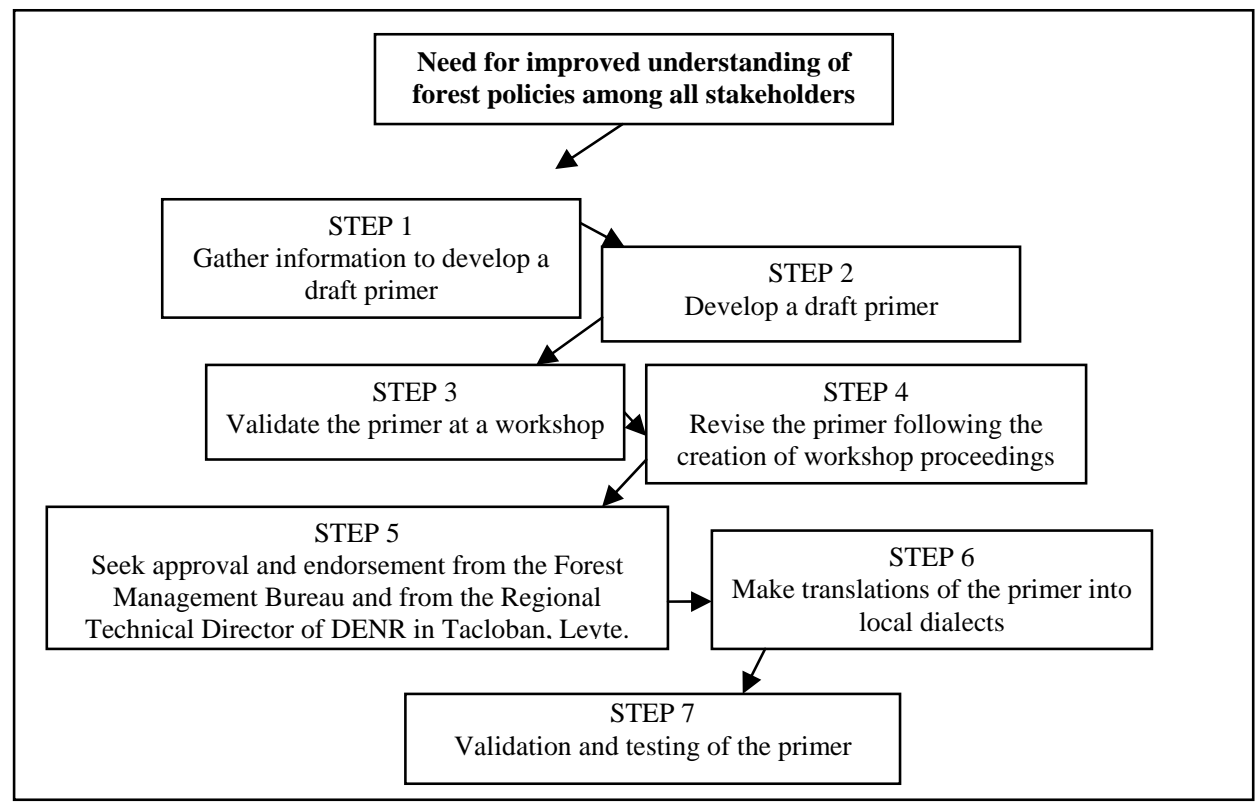

Figure 1. Steps involved in the development of the primer

Tree registration is designed to help tree farmers meet government rules and regulations concerning the harvest, log transport and marketing of timber. Registration also has some benefits in terms of security of tree tenure, and can be a mechanism to help tree farmers gain technical extension advice from a CENR officer. However, few farmers choose to register their trees (Harrison et al. 2005). About $60 \%$ of people in a survey of four rural communities in Leyte, Philippines, indicated an interest in commercial tree planting (Emtage 2004a), whereas the proportion actually planting trees for timber production was much lower. Additionally, sometimes tree registration is costly and complex, and this acts as a disincentive for tree planting (Harrison 2005). As noted by Emtage (2004b), without policy reform regarding tree registration and transport permits it is unlikely that there will be increased forestry activity. 
Policies are often created with beneficial goals, but cannot be implemented effectively due to a lack of resources (Grainger and Malayang III 2006), and this has particularly been the case for tree registration in Leyte Island. As argued by Russell et al. (2005), there needs to be a two-way flow of information within government agencies, and between government agencies and the community, to improve tree registration procedures and their implementation.

A primer has been designed as a guide for tree farmers, DENR officers, LGUs, the Philippine National Police (PNP) and other key stakeholders on National forest policy regulations. The material has been labelled as an extension primer, because it contains the 'primary' information that tree farmers can use to understand forest policy and regulations. The primer has been designed to serve as a mechanism for improved understanding regarding tree registration amongst key stakeholders - including government officers and smallholders - and will assist in an Information, Communication and Education (IEC) campaign of DENR.

The first section of the paper provides an overview of the method used to clarify tree registration and associated Philippine government policies and regulations, and a description of stakeholder legal responsibilities with regards to tree registration and transport of timber. Information obtained from key informants and literature review is reported. The process of developing extension material on DENR policies on tree registration, harvest, log transport and marketing of timber is then described. The nature of the extension primer, the steps taken in its development and the content of the primer are then outlined, and validation measures are reported.

\section{METHOD OF PRIMER DEVELOPMENT}

In developing the primer, a constructivist approach ${ }^{2}$ was adopted, which has involved gaining continued insights into the lack of effective information flow on policies related to tree registration, harvesting, transport and marketing. Important stakeholder groups were identified by literature search and through advice from personnel of the Australian Centre of International Agricultural Research (ACIAR) tree farm project ${ }^{3}$. Key informants from the various stakeholder groups (including tree farmers) provided input at three workshops on tree registration polices and practices.

\section{Identification of Stakeholders Involved in Tree Registration}

Stakeholders are defined as those people who have an interest or a 'stake' in a particular issue (Harding 1998). The DENR is a critical stakeholder in Philippines

\footnotetext{
${ }^{2}$ A constructivist approach is when reconstructions of the reality of the problem will move towards an understanding of the different views, but the inquirer remains open to new information (Guba and Lincoln 1994).

${ }^{3}$ The formal project title is: ASEM/2003/052 - Improving financial returns to smallholder tree farmers in the Philippines.
} 
forestry, as the main agency involved in the regulation of tree registration, and with a responsibility for encouraging and assisting landholders to register their trees. Discussions with DENR officers in Leyte and literature review led to identification of the following groups as having a stake in the tree registration process:

- Smallholder tree farmers

- Community Environment and Natural Resource (CENR) officers

- $\quad$ Philippines National Police (PNP) officers

- Military

- Furniture manufacturers and lumber dealers

- Illegal loggers

- Department of Environment and Natural Resource (DENR) officers

- Local Government Unit (LGU) officers

- Municipal mayors

\section{Workshops and Primer Development}

A forest policy workshop was held in Tacloban City in April 2005, in which DENR policy relating to tree registration, harvesting and log transport was discussed with key stakeholders, including officers of DENR Region 8 provincial office, CENROs and LGU representatives. DENR regulations on tree registration and log transport - which currently restrict access to markets and discourage tree planting were reviewed during this workshop. The lack of knowledge and understanding of forestry policies by tree farmers was noted (Harrison et al. 2005), and development of extension packages for tree farmers was advocated.

The forest policy workshop was followed immediately (with mostly the same participants) by an action research workshop. This was designed to develop strategies to improve the flow of information regarding tree registration, harvest and log transport policy. An IEC team was formed, and one of the planned team actions was to develop a draft primer detailing DENR policy related to tree registration, harvesting and log transport. The initial draft primer was thus created with the co-operation of the DENR, Visayas State University (VSU, previously known as Leyte State University) and researchers from The University of Queensland (UQ).

\section{STEPS IN THE DEVELOPMENT OF THE PRIMER}

The need to ensure the usefulness of the primer to tree farmers meant that it was important to include the participation of tree farmers and stakeholders in the development and validation of the primer. Figure 1 shows the steps involved in the development of the primer; these are now discussed in turn. These steps were taken after the need for improved understanding of forest policies among all stakeholders was identified. 
Step 1: Copies of DENR policies relating to tree registration, harvesting, log transport and marketing were provided by the DENR regional office in Tacloban. Additionally, policy matters were discussed at the ACIAR policy workshop, followed by the action research workshop, in Tacloban City during April 2005. The IEC team that was formed at the action research workshop, developed an action research plan, which included a timeline of activities to develop an extension primer on tree registration, harvesting, and log transport policy.

Step 2: Development of the draft primer occurred shortly after the workshops in Tacloban and involved collaboration between ACIAR project members and staff of Visayas State University, DENR, the ACIAR smallholder tree farmer project, and researchers from The University of Queensland. The primer was edited a number of times before an initial draft was circulated for comment to key stakeholders who were invited to a workshop to revise the primer.

Step 3: After creating and refining the draft primer, further discussion by the IEC team affiliated with the ACIAR smallholder tree farmer project led to the organisation of a workshop to revise the primer and to facilitate a greater sharing of knowledge amongst stakeholders. The 'ACIAR Tree Farmer Project Primer Validation Workshop’ was held in June 2005 at LSU.

Gathering stakeholders together at a primer validation workshop enabled a review and validation of a primer on policies and an opportunity to increase the communication amongst key actors. During the primer development, stakeholders implementing the policies provided information as to the methods and effectiveness of policy implementation. In that some flexibility exists for variations in implementation at the CENRO level, there are differences in implementation of tree registration and associated policies throughout Leyte. For example, the level of fees charged for CENRO field officers to travel to properties to inspect trees for registration differs between CENROs. Because of this, it was considered necessary to involve all CENR officers representing all CENROs throughout Leyte Island in the primer validation workshop. Furthermore, some CENROs have been more successful in promoting tree planting as well as devising innovative policies which appear to offer promise for wider adoption, with benefits to smallholders. These influences are a reflection of the rate of registration, where in some CENROs the number of registered tree farmers is much lower than in other CENRO areas. For example, at the time of the survey, in Baybay CENRO the number of registered tree farmers was only one tree farmer (Tan 2005).

Figure 2 shows some participants at the workshop. The key stakeholders attending the workshop included DENR representatives, tree farmers, a furniture dealer, and representatives of the PNP, UQ, VSU and The World Agroforestry Centre. Each participant at the workshop was given a copy of the draft extension primer. Initial comments on the draft were received through an open discussion amongst all workshop participants. Later, the 36 participants were split into three groups. Each 
group contained about 12 people with at least one CENRO representative, one staff member of the ACIAR tree farmer project and at least one tree farmer or industry representative. This arrangement was designed to ensure that all groups contained stakeholders with a range of perspectives (e.g. a government officer involved in implementing policies and a farmer who has tried to register and transported their trees). Each group was then asked to revise and validate the draft primer. A representative from each group then presented any changes agreed by the group. The revised versions produced by each of the three groups included changes in content (including additions), design and format, and wording of the primer. As each group presented their changes, members from other groups gave feedback on their suggestions.

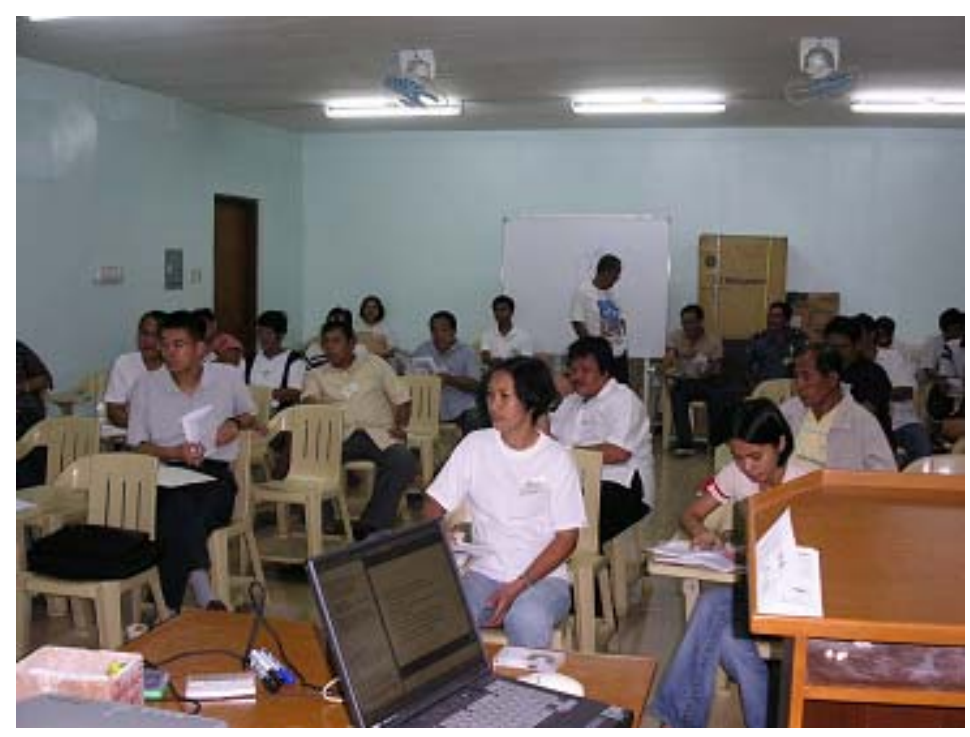

Figure 2. Participants at the Primer Validation Workshop

During the workshop, various discussions (before, during and after participants were divided into groups) were held regarding the depth, content and specific aspects of policy, including definitions of terms, fees charged for permits and benefits of tree registration. There were often differing views on what should be included in the primer and this led to some intense discussions.

Required modifications to the draft primer were identified during the primer validation workshop. A new section was added on timber marketing policy, this being suggested during the workshop by a lumber dealer, supported by CENRO personnel, and accepted by workshop participants (ACIAR 2006). Other new sections added 
included a foreword, a section on when to register trees, and a list of CENROs and their coverage areas on Leyte Island. Some existing sections were modified. The sequence of steps required for smallholders to register their trees was confirmed, but more detail was added to this section to expand on information contained in policy documents.

Stakeholders where given a greater opportunity to consider issues of ineffective implementation of policies by discussing these issues with each other. This meant that the primer validation workshop served as a mechanism to improve information flow between and amongst key stakeholder groups with regards to the tree registration policy. As a result of the primer development, practical policy guidelines were formalised in the primer to provide a tool for foresters of the DENR to use as an extension aide, to support the extension activities of DENR officers.

Step 4: All workshop discussions were audio-recorded and subsequently transcribed which assisted in the production of a workshop proceedings. The workshop proceedings provided feedback and a critical evaluation of the draft primer as it provided detail of policy requirements. Figure 3 shows the types of information that were included in the primer.

\section{Activities Following the Primer Validation Workshop}

A revised draft of the primer was not completed during the primer validation workshop. Subsequently, a smaller group was convened at the workshop to be in charge of producing a revised copy of the primer. At least one representative from each of the three working groups was selected to be a part of the final validation group. Follow -up meetings then commenced with this working group selected. The group included representatives from three different CENROs, a representative from The World Agroforestry Centre and members of the ACIAR project Information, Education and Communication team. After discussing and approving the proposed modifications to the primer, during three follow-up meetings, attachments (the Annexes listed in Figure 3) were added to the primer, and the layout and design was improved. During the third post-workshop meeting in August 2005, the draft was approved by the IEC team and other stakeholders (including staff from DENR). A final copy of the primer was then produced in August 2005.

Step 5: The primer was presented to the Forest Management Bureau at the central office in Manila, Philippines, to seek final approval and endorsement. Approval of the primer from the central office, enabled the Regional Technical Director of the DENR for Leyte region (Region 8) in Tacloban and CENRO officers to endorse the primer. Subsequently, the primer has been received and signed by the Regional Technical Director. The extension material needed to have a signature from a higher authority, before it could be used as an extension tool for CENR officers to improve policy implementation. In addition, a signature from higher authority is useful because some tree farmers do not trust CENR officers. Furthermore, in the past there has been conflict among the PNP and CENR officers over specific requirements of forestry 
policy, and the centrally endorsed primer provided an authoritative document to resolve such conflicts in the future.

Step 6: The English version of the primer was translated to local Cebuano and Waray Waray dialects. Feedback is currently being obtained from tree farmers on these translated versions. Key stakeholders - including tree farmers and CENRO personnel - have received copies of the primer. In support of the dissemination of the primer, training for CENROs and LGUs will take place and information contained in the primer has been broadcast over radio DYAC from VSU.

Step 7: Further validation of the primer has been conducted to seek out how much the primer is used by all stakeholders, how informative and understandable it is and whether the flow of information regarding policies is improved.

\section{CONTENT OF THE PRIMER}

The final version of the primer contains readily understandable information about government requirements and procedures for tree farmers. Text is supported by illustrations, to make it more visually appealing. Figure 3 provides a summary of the groups of information contained in the primer. Figure 4 presents the front cover of the primer.

Much of the content of the primer details word-for-word information from DENR policy documents, but this is supported by additional explanation. The primer expands on some important issues, including why people would benefit from registering their trees. However, care has been taken to use wording consistent with that in the policy documents, because the implication of the wording must correspond with legal documents. For example, a definition of a plantation could not be included in the primer because there is no definition in DENR policy documents.

When the primer was translated to Cebuano and Waray Waray dialects, there was a need to ensure that the wording would be interpreted in the same way as the English version. Copies of the primer have been distributed to the intended users. Likewise, the Primer served as a reference for the design and implementation of the school-onthe-air (SOA) on tree farming policies at VSU Radio DYAC. Currently, a field evaluation is being conducted to gather users' feedbacks on the primer. 


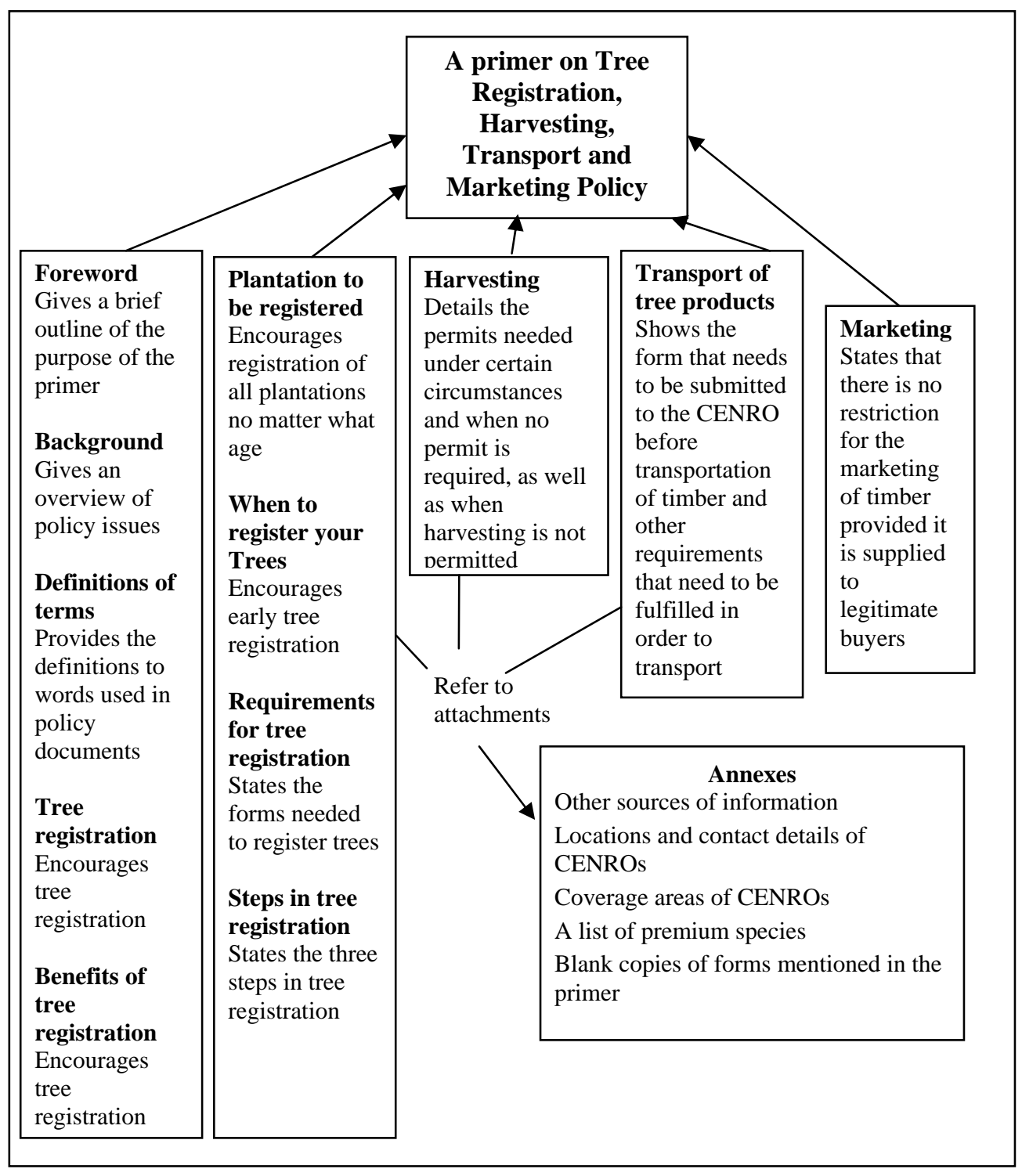

Figure 3. Types of information contained in the primer 


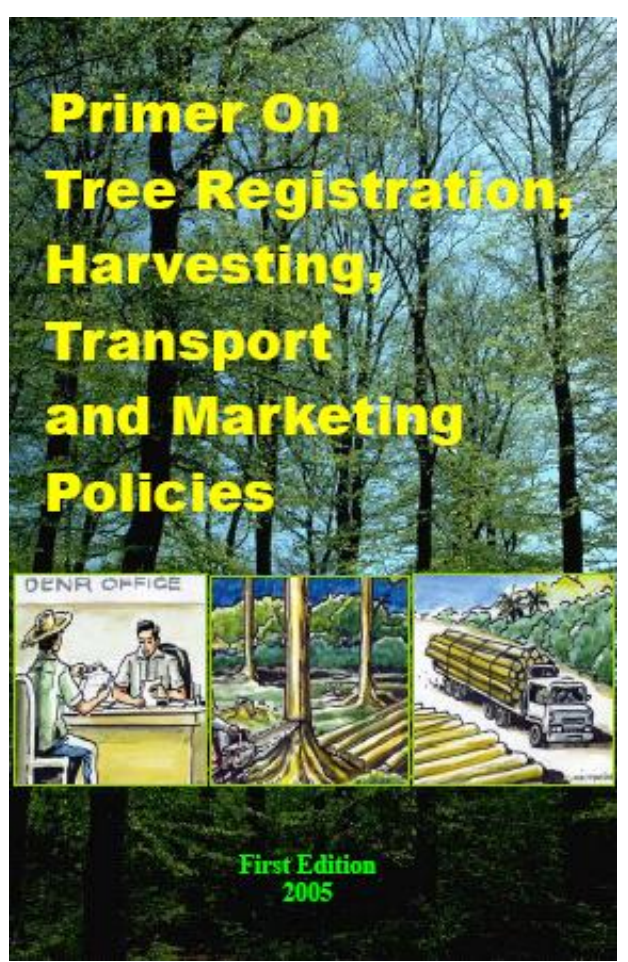

Figure 4. The front cover of the primer

\section{Highlights of the Primer's Contents}

The primer features the timing of tree registration, and the benefits derived from registering trees. DENR regulations allow farmers to register their trees at any age. This information is included in the primer under the section 'When to register trees'. However, early tree registration assists DENR by including the details of each tree farmer's trees in a database. Early tree registration is encouraged in the primer, although the primer also states that trees can be registered at any age, because registration is important for helping provide extension advice and inputting tree farm information into a database.

The primer lists a number of the benefits of tree registration for the tree farmer, including ${ }^{4}$ :

\footnotetext{
${ }^{4}$ These points serve as an incentive for smallholders to register their trees, although it has been argued by some key informants that these benefits do not apply under all circumstances. These benefits are the perspective benefits provided by many of the workshop participants including DENR staff.
} 
- easy to secure a permit to harvest and transport timber.

- access to free technical assistance from DENR and related agencies, especially on tree growing technologies and marketing.

- better access to potential buyers through DENR information system resulting in a better price for timber.

- exemption from forest charges and other environmental fees.

- trees will be recorded in a DENR database, which will be useful in linking products to buyers

\section{CONCLUSION}

It was found that when a tree farmer wishing to harvest their timber is well informed about the requirement for tree registration, has a positive relationship with the CENRO and is able to obtain free tree registration, they are willing to register their trees. On the other hand, when registration is costly, takes a long time and the tree farmer does not trust the CENRO, they are less likely to register their trees. It was found that other than resource constraints to effective tree registration, there is also a lack of effective information flow on DENR tree registration policies, which has caused conflict between stakeholders.

The primer on tree registration, harvesting, transport and marketing policy has undergone a rigorous process of development and validation by key stakeholders. The primer has been evaluated and is ongoing as another step in its development. Success has been judged upon whether tree farmers in Leyte are better informed about forest policy, and whether implementation of the tree registration policies is improved due to more effective IEC resulting from use of the primer. The process of developing the primer has constituted an improvement in communication itself, and has served as a tool to help improve tree registration, harvest, transport and marketing policy development.

\section{ACKNOWLEDGMENTS}

Development of the primer has been a collaborative effort by members of the ACIAR tree farmer project team and others, involved in a number of workshops and other activities for primer production and validation. In particular, we would like to thank John Herbohn, Edwin Cedamon and Janet Cedamon. We also thank Belita Vega from Visayas State University. Thanks are also due to personnel of the DENR, PNP and other key stakeholders who provided information for the study and those that participated in workshops and activities. Rosela B. Sabejon and Arniel Pogosa assisted in conducting field work. Steve Harrison and Iean Russell provided supervision to the first author in undertaking an Australian Youth Ambassador for Development volunteer project which helped initiate development of the primer. 


\section{REFERENCES}

ACIAR, DENR, LEYTE STATE UNIVERSITY and THE UNIVERSITY OF QUEENSLAND. 2005. A Primer on Tree Registration, Harvesting, Transport and Marketing Policies. Leyte State University, Visca, Baybay, Leyte, the Philippines.

ACIAR. 2006. Proceedings from ACIAR Tree Farmer Project Primer Validation Workshop. Leyte State University. Visca, Baybay, Leyte.

ARBIOL, R. (CENRO). 2005. Pers. comm. Previously CENR officer of Maasin, Maasin City, Leyte, the Philippines, currently a PENRO in Catarman, Samar, the Philippines.

CALUB, F.S. 2005. DENR rules and regulations governing timber and timber products planted on private land. Annals of Tropical Research. 27(1): 91-96.

DENR. 1997. Documentation of Tree Plantations in Private Lands. DENR Memorandum Circular No. 97-09, Manila.

EMTAGE, N.F. 2004a. An Investigation of the Social and Economic Factors Affecting the Development of Small-scale Forestry in Leyte Province, the Philippines. PhD thesis. School of Natural and Rural Systems Management, The University of Queensland, Brisbane.

EMTAGE, N.F. 2004b. Stakeholders Roles and Responsibilities in the Community-Based

Forest Management Program of the Philippines. Small-Scale Forest Economics. Management and Policy. 3(3): 319-336.

FARM AND RESOURCE MANAGEMENT INSTITUTE. 2005. Leyte State University. Visca, Baybay, Leyte, the Philippines.

GUBA, E.G. and Y.S. LINCOLN. 1994. Competing Paradigms in qualitative research. In: Handbook of Qualitative Research. (N.K. Denzin and Y.S. Lincoln, eds). Sage, Thousand Oaks, CA,. pp. 105-117.

GRAINGER, A. and B.S. MALAYANG III. 2006. A model of policy changes to secure sustainable forest management and control of deforestation in the Philippines. Forest Policy and Economics. 8(1): 67-80.

HARDING, R. (ed.) 1998. Environmental Decision-making: the Roles of Scientists, Engineers and the Public. The Federation Press, Sydney.

HARRISON, S. 2005. Institutional and Political Factors Affecting the Development of Smallholder Forestry in Leyte Province. ACIAR End of Project Workshop Proceedings. Sabin Resort Hotel, Ormoc, Leyte, the Philippines, 19-21 August 2003.

HARRISON, S., RUSSELL, I., MANGAOANG, E. AND J. HERBOHN. 2005. Report of ACIAR Project ASEM/2003/052 Initial Policy Workshop and Action Research Workshop. Tacloban, Leyte, the Philippines.

RUSSELL, I., MANGAOANG, E., HARRISON, S., HERBOHN, J. and J. BAYNES. 2005. An approach to improving the flow of information for forestry regulation in the Philippines: trees for life and livelihood. ACIAR Smallholder Forestry Project ASEM/2003/052, Project Planning Workshop, Ormoc City, Leyte, 15-17 February 2005. 
TAN, E. 2005. Pers. comm. CENRO Baybay and ACIAR Tree Farmer Project, Baybay, Leyte, the Philippines.

VILLAMOR, G.B. In press. The rise of protected area policy in the Philippine forest policy: An analysis from the perspective of Advocacy Coalition Framework (ACF). Forest Policy and Economics. 